\title{
3-ROUTES PLATFORM FOR RECOVERY OF HIGH VALUE PRODUCTS, ENERGY AND BIO-FERTILIZER FROM URBAN BIOWASTE: THE REVENUE PROJECT
}

\author{
Agata Gallipoli ${ }^{1}$, Andrea Gianico ${ }^{1}$, Simona Crognale ${ }^{1}$, Simona Rossetti ${ }^{1}$, Leone Mazzeo ${ }^{2}$, \\ Vincenzo Piemonte ${ }^{2}$, Maurizio Masi ${ }^{3}$ and Camilla M. Braguglia ${ }^{1, *}$ \\ ${ }^{1}$ Water Research Institute, National Research Council, Via Salaria km 29,300, 00015 Monterotondo (Rome), Italy \\ ${ }^{2}$ Department of Engineering, University Campus Biomedico of Rome, Via Alvaro del Portillo, 21, 00128 Rome, Italy \\ ${ }^{3}$ Polytechnic University of Milan, Department of Chemistry, Materials \& Chemical Engineering, Piazza Leonardo da Vinci 32,20133 \\ Milano, Italy
}

Article Info:

Received:

3 February 2021

Revised:

22 April 2021

Accepted:

30 April 2021

Available online:

30June 2021

Keywords:

Food waste

Biorefinery

Methane

VFAs

Hygienization

Downstream processing

\section{ABSTRACT}

This innovative Biorefinery platform is based on the integration of a mild thermal pre-treatment and a solid/liquid separation unit to parallel-integrated bioprocesses specifically selected on food waste distinctive chemical composition: a liquid fraction, rich in readily fermentable sugars, to be transformed into valuable biobased products, and a solid organic residue to enhance biomethane production generating a fully hygienized digestate to be recycled. The preliminary results in terms of VFAs yields and composition from the acidogenic stage, and the methane conversion rate from the anaerobic digestion of the solid residue, are here presented. The integration of a mild thermal pretreatment promoted the transformation and the conversion rates into volatile fatty acids through the optimization of operational $\mathrm{pH}$ and HRT of the primary fermentation step. Secondary fermentation reaction as chain elongation to MCFAs (as caproic acid) occurred in the same reactor without external donor addiction probably because of the in situ formation of lactate. The solid residue fed into semi-pilot anaerobic digesters assured process stability (no acidification phenomena occurred) despite the short HRT of $20 \mathrm{~d}$. The weakening of the lignocellulosic matrix by the thermal pre-treatment had a positive impact on the anaerobic conversion increasing methane production (+20\%), in particular during weekend, when feeding was stopped.

\section{INTRODUCTION}

In circular bioeconomy, the recycling of biowaste is a crucial strategy for optimizing the use of the available biomass resource base in order to promote a comprehensive sustainable FW management system, stimulated by the increasing awareness of the exhaustion of non-renewable natural resources (Agler et al. 2011; Braguglia et al., 2018; Coma et al., 2017; Kleerebezem and van Loosdrecht 2007). Urban biowaste is traditionally seen as a costly problem in economic and environmental terms. This equation can be reversed by designing more effective recovery and processing systems to turn organic waste into a source of value and contribute to restoring natural capital. Biorefineries could be a central technology in this endeavor (Alibardi et al., 2020). Operating in a similar way to petrochemical refineries, they employ a range of techniques - such as feedstock pretreatments, biological processes, enzymat- ic conversions - to transform source separated biowaste into valuable chemicals, products and energy. In Italy, in the last decade, intensive source separation of biowaste (food waste, FW, and green park waste, GW), has been extended also to medium/large towns and metropolitan areas, attaining best-practice performances in terms of quantity and quality of the collected biowaste.

Anaerobic digestion (AD), regarded by EU waste legislation as ideal recycling operation in the framework of the circular economy, is currently considered as one of the best environmental-friendly alternatives, because of its limited environmental footprints, high potential for energy recovery, producing carrier material for biofertilizers. However, the economic value of biogas and digestate is limited, enabling the development of alternative processes that yield higher-value endproducts. Carboxylic acids as acetate, propionate, butyrate and valerate, have a wide variety of applications in the chemical industry, mainly as bulk 
industrial chemicals (Arslan et al., 2016), in the production of bioplastics (Zacharof and Lovitt 2013; Valentino et al., 2019), biofuels and chemicals (Lee et al., 2014), or in biological nutrient removal. The conversion of organic waste to bulk chemicals is 3.5 to 7.5 times more profitable than its conversion to biomethane (Pfaltzgraff et al., 2013). At the same time, the European energy target from renewable sources (Eurostat, 2020) is 20\% (by 2020) and at least $32 \%$ by 2030 (Italy reached $17.8 \%$ in 2018).

Moreover, it is well known that anaerobic digestion of Food waste to produce biomethane is often limited by system instability induced by FW characteristics. The availiability of prompt biodegradable carbohydrate fraction of FW was shown to allow the establishment of stable and active fermentative populations (Tonanzi et al., 2018) with the reduction and progressive inhibition of methanogenic biomass, thereby resulting in VFA accumulation and a $\mathrm{pH}$ decrease until biomethane drop (Capson-Tojo et al., 2016; Tonanzi et al., 2020, Zhang et al., 2012).

The innovative 3 -Routes Platform proposed here is based on the integration of a thermal pretreatment capable of significantly increasing the fraction of fermentable organic carbon from FW. The final goal is changing the status of the feedstock to become more suitable for the production of high-value products as short-medium chain fatty acids from the liquid stream, and biomethane (and hygienized digestate) from the solid residue.

Pretreatment has been a major argument of research during the past 30 years and the $A D$ improvement in terms of increased solubilization and $\mathrm{H}_{2} / \mathrm{CH}_{4}$ yields are well established, in particular for sludge (Braguglia et al., 2018; Carrère et al., 2016; Cesaro and Belgiorno, 2020). Very few studies (Kleerbezem et al., 2015; Zhang et al., 2019), aimed for determining the impact of pretreatment on VFAs production potential from FW as proposed here. Mild thermal pretreatment can, in fact, significantly alter both physical and chemical properties of FW, resulting generally in increased solubilization (Pagliaccia et al., 2016, 2019; Montecchio et al., 2017), in reduced lignocellulosic matrix, and improved digestate hygienization (Ariunbataar et al., 2015). Cellulose, hemicellulose and lignin containing wastes as OFMSW (source separated organic fraction) and FW (Romero-Cedillo et al., 2017), need further pretreatment in order to make the substrate more accessible to microbial degradation (Loow et al., 2016). Pecorini et al. (2016) reported increase of soluble COD, carbohydrates and proteins concentration in the pretreated OFMSW sample, while lignocellulosic and starch fraction were found to be lower in the pretreated FW by Pagliaccia et al. (2019).

The strategies for enhancing VFAs production is to promoting the acidogenic process, by inhibiting the methanogenesis, operating a bioreactor with optimized operative conditions and feeding patterns. The selective production of organic acids from various feedstocks is an emerging field of research. Which fermentation products are produced during the fermentation step, under which conditions and by which microorganisms represent open questions receiving increasing attention in recent years, but to our knowledge, only few studies focused the attention on hydrolysis enhancement with feedstock pretreatment, by treating sludge not FW (Morgan-Sagastume et al., 2011; Zhang et al., 2019). Numerous environmental factors determine the product spectrum of mixed culture fermentations, and the microorganisms dominating the system. This project fills the knowledge gap by investigating the impact of operative conditions on fermentation process performances (VFA composition, yields, stability) together with quantitative, predictive relationships between the complex microbial community structure and the fermenter functional outputs (Crognale et al., 2021). Correlation between the microbial community structure and the fermentation process performances is still a field full of gaps, especially in the case of semi-continuous long term processing with real feedstock.

The innovative rationale of this approach, never investigated up to now, is to exploit the potential of thermal pretreatment of food waste in solubilizing carbohydrates and proteins, in order to investigate the impact on acidogenesis in terms of VFAs yield and product spectrum. The economic value of VFAs produced during anaerobic digestion is intrinsically high, but further processing and conversion of this mixed carboxylates can enhance economic benefits even more (Marshall et al., 2013). One biological post-processing step investigated in this project is the microbial chain elongation of the short chain carboxylates into longer chain products as caproic acid, via syntrophic interactions, when reduced compounds as lactate or ethanol (electron donor) are added (Steinbush et al., 2011).

In this project, the challenge is to minimize (or completely avoid) the addition of external donor by steering the hydrolysis and acidogenesis stage introducing the thermal pretreatment step of the food waste substrate to improve both organics hydrolysis and the successive fermentation and/or chain elongation process by starting from real biowaste. The microbiome responsible for VFA production and chain elongation will be investigated by means of several biomolecular tools including high-throughput $16 \mathrm{~S}$ rRNA gene sequencing. For the first time, in this project, amphiphilic ty nanoparticles will be applied to investigate the fatty acids adsorption potential from fermentation broth.

The preliminary results in terms of VFA composition and yield of semicontinuous fermentation tests of the liquid extract, and methane yield by the anaerobic digestion of the residual solid phase, are here presented and discussed, for untreated and thermal pretreated food waste.

\section{MATERIALS AND METHODS}

\subsection{Substrates}

FW was collected from the cafeteria of the research area "Roma 1" of the National Research Council. The cafeteria produces approximately $400 \mathrm{~kg}$ of FW per week, which consisted of mixed cooked and uncooked food such as pasta, rice, soup, bread, fruit and vegetable peelings. After sampling, the FW underwent an accurate manual screening to match the quantities of the various fractions with the chosen composition: $70 \%$ fruit and vegetable waste, $15 \%$ pasta and bread and $15 \%$ dairy residues. Successively, sorted scraps were shredded by a food processor, prior to 
being stored at $-20^{\circ} \mathrm{C}$. The anaerobic inoculum used for the start-up of the acidogenic tests was extracted from a labscale fermenter fed with FW and then acclimated to liquid extract, while the inoculum for the biomethane potential tests (BMP) and the anaerobic digestion of FW residues was obtained from a full-scale digester treating sewage sludge.

\subsection{Thermal pretreatment}

The frozen FW sample was thawed and mixed with tap water $(1: 4 \mathrm{w} / \mathrm{w})$ to maximize the effectiveness of pretreatment, namely a hydrothermal treatment carried out in a bench scale autoclave Laboklav $25 \mathrm{~b}$, with total capacity of $25 \mathrm{~L}$ (SHP Steriltechnik AG, Germany). Operative temperature and pressure were set at mild conditions, namely $\mathrm{T}=134^{\circ} \mathrm{C}$ and $\mathrm{p}=3.2$ bar. Retention time was set at 20 minutes on $2.5 \mathrm{~L}$ of sample. The applied specific thermal energy resulted around $9250 \mathrm{~kJ} / \mathrm{kgTS}$.

\subsection{Liquid solid separation unit}

The liquid/solid separation phase on raw and pretreated FW was performed with a bench scale centrifuge Rotanta 460 (Hettich, Germany) operating at 4600 rpm for 10 $\min$. The liquid phase was successively filtered through a $0.5 \mathrm{~mm}$ mesh sieve to remove the coarse residue particles (Figure 1).

\subsection{Analytical methods}

Total and volatile solids were determined according to standard methods (APHA, 1998). The $\mathrm{pH}$ was detected by a portable $\mathrm{pH}$ meter Eutech Instruments $\mathrm{pH} 700$. Soluble (sCOD), total COD and total nitrogen, measured in duplicates, were determined by means of COD Cell Test (EPA method 410.4) and the Nitrogen Cell test (EN ISO 25663) by Spectroquant Merck. Proteins and carbohydrates were measured on filtered liquid samples (glass filters GF/C Whatman, $1.2 \mu \mathrm{m}$ porosity). Protein content was determined by bicinchoninic acid protein assay (Sigma Aldrich) using standard solution of bovine serum albumin (Smith et al., 1985). Carbohydrates determination was based on a modified DuBois method (Braguglia et al., 2012; DuBois et al., 1956). Total proteins content was estimated by multiplying the total organic nitrogen content by a factor of 6.25 .
The biogas composition was measured using a PerkinElmer Auto System Gas Chromatograph equipped with a thermal conductivity detector (TCD) as described in Gianico et al. (2013). Volatile fatty acids (VFA) were analysed by injecting $1 \mu \mathrm{L}$ of filtered $(0.22 \mu \mathrm{m}$ porosity) liquid sample into a Perkin Elmer Auto System gas-chromatograph equipped with a FID detector (flame ionization detector) as reported in Gagliano et al. (2015)..

\subsection{BioMethane potential tests (BMP)}

BMP tests on raw and pretreated FW were performed in mesophilic conditions $\left(37^{\circ} \mathrm{C}\right)$ by using the Automatic Methane Potential Test System (AMPTS-II, Bioprocess Control, Sweden), equipped with $500 \mathrm{~mL}$ reactors, mechanically stirred and heated, and $\mathrm{CO} 2$ removal units. Substrate and inoculum were mixed at a feed to inoculum ratio $(F / I)$ of 0.5 and 1 , on volatile solids (VS) basis. More experimental details in Gallipoli et al., 2020.

\subsection{Acidogenic step with liquid extract}

Two parallel 3 Liters semi-continuous fermenters were operated at $37^{\circ} \mathrm{C}, \mathrm{HRT}$ of $4 \mathrm{~d}$ and $\mathrm{pH}=6$ (controlled with $\mathrm{Na}_{2} \mathrm{CO}_{3} 2.7 \mathrm{M}$ addition, when needed), and manually shaken several times a day. For the start-up of the fermentation tests, both reactors were filled with $3 \mathrm{~L}$ of acidogenic inoculum. Two acidogenic fermentation tests were carried out on untreated FW extract (organic loading rate OLR $=5 \mathrm{gCOD} /$ $\mathrm{L}_{\text {reactor }} \mathrm{d}$ ) and pretreated FW extract (OLR $=9 \mathrm{gCOD} / \mathrm{L}_{\text {reactor }}$ d), respectively. Methane was measured online ( $\mu$ Flow, Bioprocess Control, Sweden), after the $\mathrm{CO}_{2}$-fixing unit.

\subsection{Anaerobic digestion of the residue}

Two parallel 8 Liters semi-continuous anaerobic digesters (CSTR) were operated at $37^{\circ} \mathrm{C}$, at hydraulic retention time (HRT) of $20 \mathrm{~d}$ and $\mathrm{OLR}=1.6 \mathrm{gVS} / \mathrm{L}_{\text {reactor }} \mathrm{d}$ by feeding untreated and pretreated FW solid residues. For the startup, each reactor was filled with methanogenic inoculum and then acclimated to FW for a period of $1 \mathrm{HRT}$. The produced biogas was collected and sent through $\mathrm{CO}_{2}$ traps ( $\mathrm{NaOH} 3 \mathrm{M}$ solutions) and to the methane detection units ( $\mu$ Flow, Bioprocess Control, Sweden) for gas volume measurement at $\mathrm{T}=0^{\circ} \mathrm{C}$ and $\mathrm{p}=1 \mathrm{~atm}$.

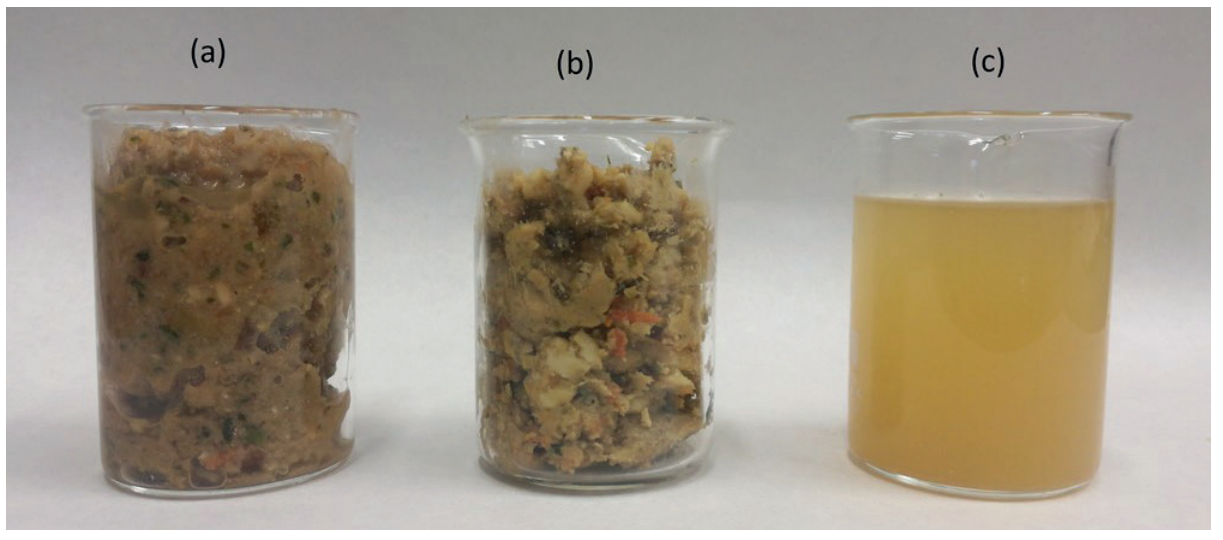

FIGURE 1: The Food waste (a), the solid residue (b) and the liquid extract (c) obtained after pretreatment and centrifugation. 


\section{RESULTS AND DISCUSSION}

\subsection{Characterization of household food waste}

The FW characterization showed an average acidic $\mathrm{pH}$ of $4.5 \pm 0.2$, high content of water, due to the high percentage of vegetables, and high organic content (VS $=95 \pm 2 \% \mathrm{TS}$ ), highlighting high transformation potential of the substrate in bioprocesses as AD and fermentation. The organic matter was mapped in terms of proteins, carbohydrates, lignocellulosic components, lipids and Volatile Fatty Acids (VFAs). VFAs content in the fresh matrix was almost insignificant, accounting for not more than $2 \%$ of the total organic matter expressed as total COD, suggesting no pre-fermentation phenomena due probably to the rapid freezing storage after collection. Total carbohydrates accounted for $60 \%$, while proteins and lipids fraction was $16 \%$ and $6 \%$ of the total COD, respectively. Soluble carbohydrates content ( $21 \%$ of COD) was high due probably to the high water content combined with the grinding phase acting as physical pretreatment. It is important to note that this type of FW presents also a lignocellulosic matrix (cellulose + hemicellulose + lignin) accounting for $19 \pm 2 \%$ of the total solids, due to the high fraction of vegetable and fruit wastes (Pagliaccia et al., 2019).

The liquid $(43 \%, w / w)$ and solid $(57 \%, w / w)$ fraction deriving from raw food waste separation unit were characterized (Table 1). Most of the total solids, rich in organics (VS/TS=97\%), remained in the residual fraction, with a total COD mainly in particulate form ( $15 \%$ was soluble). As regards the liquid extract, all the COD was composed by soluble substances, in particular carbohydrates (around $70 \%$ expressed as COD).

\subsection{Thermal pretreatment effect}

The thermal pretreatment carried out with autoclave with an optimized duration of 20 min did not affect solids and organic content, but the inherent distribution between particle and soluble forms (Gianico et al., 2013). Pretreatment was effective in the solubilisation of the FW macromolecular fractions, resulting in a $+57 \%$ increase in the soluble organics, both proteins and sugars. The pretreatment, despite the mild temperature and pressure conditions, was able to reduce the recalcitrant lignocellulosic matrix by breaking the interlinkages making more bioavailable the trapped compounds (Montecchio et al., 2017).
The main characteristics of liquid extract $(83 \% \mathrm{w} / \mathrm{w})$ and solid residue $(17 \% \mathrm{w} / \mathrm{w})$ deriving from the pretreated, diluted, FW are reported in Table 1. It is important to note that the thermal pretreatment resulted highly efficient in transferring the colloidal fraction of COD into the extract. The total COD of the raw extract was, in fact, totally constituted by soluble COD, while the pretreated one presented a noticeable fraction (around 30\%) of sovra-colloidal COD, probably due to starch solubilization. Moreover, after the pretreatment, the residue was depleted by a significant fraction of solids, transferred into the liquid extract.

\subsection{Effect of thermal pretreatment on acidification stage}

In order to assess the potential of both raw and thermal pretreated FW to be fermented and/or to produce $\mathrm{CH}_{4^{\prime}}$ different batch tests were performed at different $\mathrm{F} / \mathrm{I}$ ratios (feed to inoculum ratio in terms of organics content) using an anaerobic inoculum from full-scale digester treating sludge containing also methanogens. Thermal pretreatment reduced the inert fraction of the FW from 22 to $17 \%$, enhancing biodegradability. All tests reported a fast carbohydrate consumption: independently from the initial concentration, most of the soluble carbohydrates in the reactors was easily transformed into VFAs and hydrogen. Nevertheless, just after one day, operating the reactors at higher load (i.e. F/I = 1), dramatic VFA accumulation (mostly butyrate) took place, due to the fermentation of $70 \%$ of the bioavailable soluble carbohydrates.

The liquid extracts obtained from the solid-liquid separation unit (see Table 1) have been characterized in terms of COD before the acidogenic step, and appropriately diluted (only in the case of the untreated extract) in order to achieve the desired OLR.

A preliminary study on fermentation performances of the liquid "extract" deriving from raw and pretreated FW was performed in semi-continuous mode. Acidogenic fermentation was evaluated in terms of the amounts of VFAs produced, VFA composition, and fate of the carbohydrates. Promising fermentation yields of VFAs (from acetic to caproic acid) of $0.37 \pm 0.3 \mathrm{~g} / \mathrm{gVS}_{\text {fed }}$ and $0.49 \pm 0.4 \mathrm{~g} / \mathrm{gVS}$ fed were obtained after 3 HRTs of operation, with raw and pretreated feed respectively, with comparable acidification degree $\left(\mathrm{COD}_{\mathrm{VFA}} / \mathrm{SCOD}\right)$ of $85 \pm 2 \%$. It was interesting to note

TABLE 1: Characteristics of liquid extract and solid residue of raw and thermal pretreated FW.

\begin{tabular}{|c|c|c|c|c|}
\hline & \multicolumn{2}{|c|}{ Raw FW } & \multicolumn{2}{|c|}{ Pretreated FW } \\
\hline & Liquid extract & Solid residue & Liquid extract * & Solid residue \\
\hline $\mathrm{pH}$ & $5.1 \pm 0.2$ & $4.4 \pm 0.2$ & $4.7 \pm 0.1$ & $4.7 \pm 0.3$ \\
\hline TS (g/L) & $68.8 \pm 2.5$ & $285 \pm 14$ & $28.0 \pm 1.3$ & $180 \pm 12$ \\
\hline VS (g/L) & $58.5 \pm 2.0$ & $276 \pm 10$ & $25.2 \pm 1.2$ & $175 \pm 10$ \\
\hline $\operatorname{COD}(g / L)$ & $75.7 \pm 6.4$ & $288.9 \pm 29$ & $34.1 \pm 4.6$ & $194.1 \pm 27$ \\
\hline $\operatorname{sCOD}(\mathrm{g} / \mathrm{L})$ & $72.6 \pm 3.6$ & $42.3 \pm 6.8$ & $25.6 \pm 2.6$ & $46.1 \pm 9.2$ \\
\hline Soluble Proteins (g/L) & $18.4 \pm 2.6$ & $11.2 \pm 1.7$ & $3.8 \pm 0.5$ & $11.3 \pm 1.5$ \\
\hline Soluble Carbohydrates $(\mathrm{g} / \mathrm{L})$ & $45.6 \pm 4.4$ & $23.2 \pm 3.2$ & $10.8 \pm 2.7$ & $24.5 \pm 4.9$ \\
\hline
\end{tabular}

* Before thermal pretreatment, the FW sample was mixed with tap water $(1: 4 \mathrm{w} / \mathrm{w})$ 
that caproic acid was produced during both tests without external donor addition, and the pretreatment seemed to favor the chain elongation pathway. The yield observed at quasi-steady state for the pretreated FW extract was 0.08

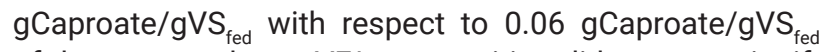
of the untreated one. VFA composition did not vary significantly between the two tests, predominant was always acetate followed by butyrate and propionate. However, in the case of the untreated extract, valerate was $17.6 \%$ against $7.8 \%$ of the pretreated (average quasi-steady state values), while the caproate fraction was comparable around $14 \%$ (Figure 2).

Undissociated acid concentration increase caused toxicity phenomena to reactor microbiome that controlled itself by not producing more caproic (see HRT 7, Figure 2) and kept the inhibition down despite the substrates availability. A continuous product extraction would address this limitation (Crognale et al., 2021; Kannengiesser et al., 2018).

\subsection{Effect of thermal pretreatment on methane pro- duction}

The effect of thermal pretreatment on biogas production rate of this food waste was previously assessed by single-stage anaerobic batch tests (Gallipoli et al., 2020). After an initial hydrogen production rate of 10 and $27 \mathrm{~mL}$ $\mathrm{H}_{2} / \mathrm{g} \mathrm{VS}_{\text {fed, }}$ the methane yield was statistically comparable, namely $0.38 \pm 0.014$ and $0.37 \pm 0.010 \mathrm{~mL} \mathrm{CH}_{4} / \mathrm{gVS}_{\text {fed }}$ for raw and thermal pretreated $\mathrm{FW}$, respectively.

The performance of the parallel digesters fed with untreated and pretreated solid residue was monitored under the same OLR of $1.6 \mathrm{~g} \mathrm{VS/L.d} \mathrm{and} \mathrm{HRT} \mathrm{of} 20 \mathrm{~d}$. In particular, Figure 3 shows the cumulative methane production along the entire operation period of 70 days, including the production of Saturdays and Sundays, when the feeding was stopped. It is important to note that after 2 weeks of start$u p$, the slope of the curve remained almost constant $\left(r^{2}\right.$ of
0.99) with $2.6 \mathrm{~L} / \mathrm{d}$ and $2.8 \mathrm{~L} / \mathrm{d}$ for untreated and pretreated residue, respectively, because of the remarkable methane production during the weekend despite the absence of feeding. It is therefore very likely that, because of the stop feeding, microorganisms had time to degrade and transform the bio-available cellulose and hemicellulose fraction of the residue into methane. Moreover, the thermal pretreatment likely undermined the lignocellulosic matrix, having a positive impact on the anaerobic conversion that was $0.31 \pm 0.01$ against $0.26 \pm 0.01 \mathrm{~L} \mathrm{CH}_{4} / \mathrm{gVS}$ fed of the untreated one.

The typical instability problem due to acidification and methane drop observed just after the first HRT by feeding food waste (Tonanzi et al., 2018; Tonanzi et al., 2020), in this case was overwhelmed probably because of the lack of soluble bio-available COD (Figure 3 ).

\section{CONCLUSIONS}

Food waste is currently a significant environmental problem that needs to be properly tackled. In this Project, its conversion to added-value products and energy within a biorefinery perspective fits well in the Circular Economy approach as it promotes a more efficient utilization of renewable raw materials, contributing to the goals of the European Green Deal (i.e to strive for greener industry and to produce clean energy). The integration of a mild thermal pretreatment assured an efficient organics solubilization (in particular sugars) into the liquid phase favoring the transformation and the conversion rates into volatile fatty acids through the optimization of operational $\mathrm{pH}$ and HRT of the primary fermentation step.

Secondary fermentation reaction as chain elongation to MCFAs (as caproic acid) occurred in the same reactor without external donor addiction probably because of the in situ formation of lactate. The innovative technological components of the proposed biorefinery will also include the use of magnetic nanoparticles to recover the most val- (a)

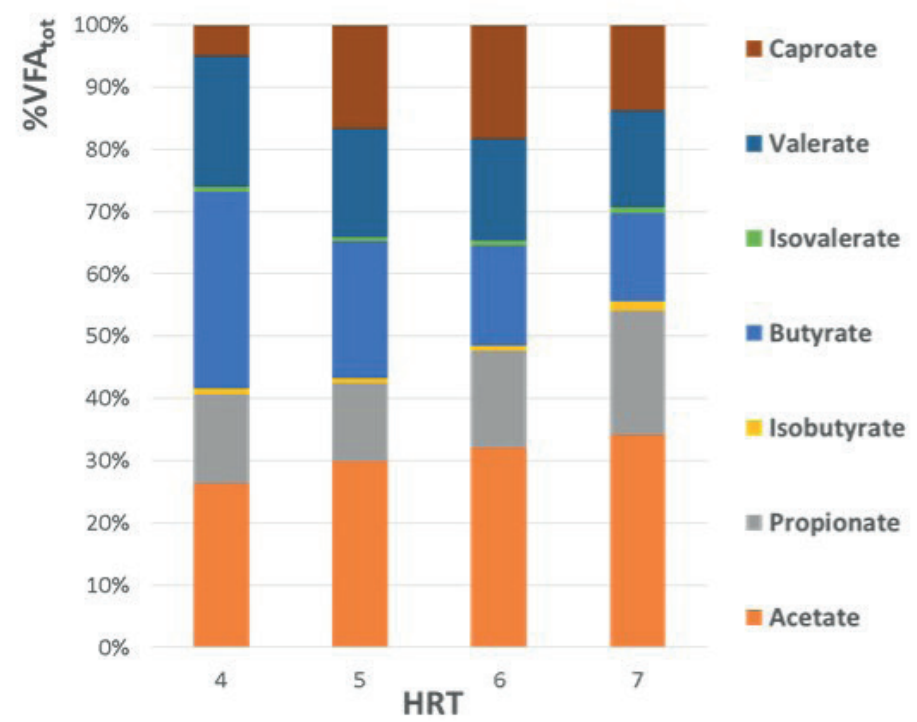

(b)

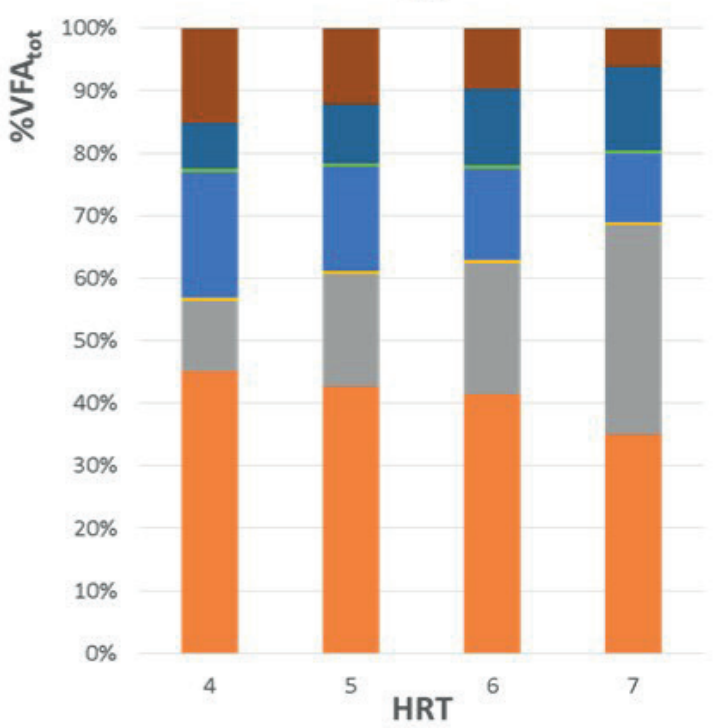

FIGURE 2: VFAs distribution of untreated (a) and pretreated (b) extract, at quasi-steady state conditions. 


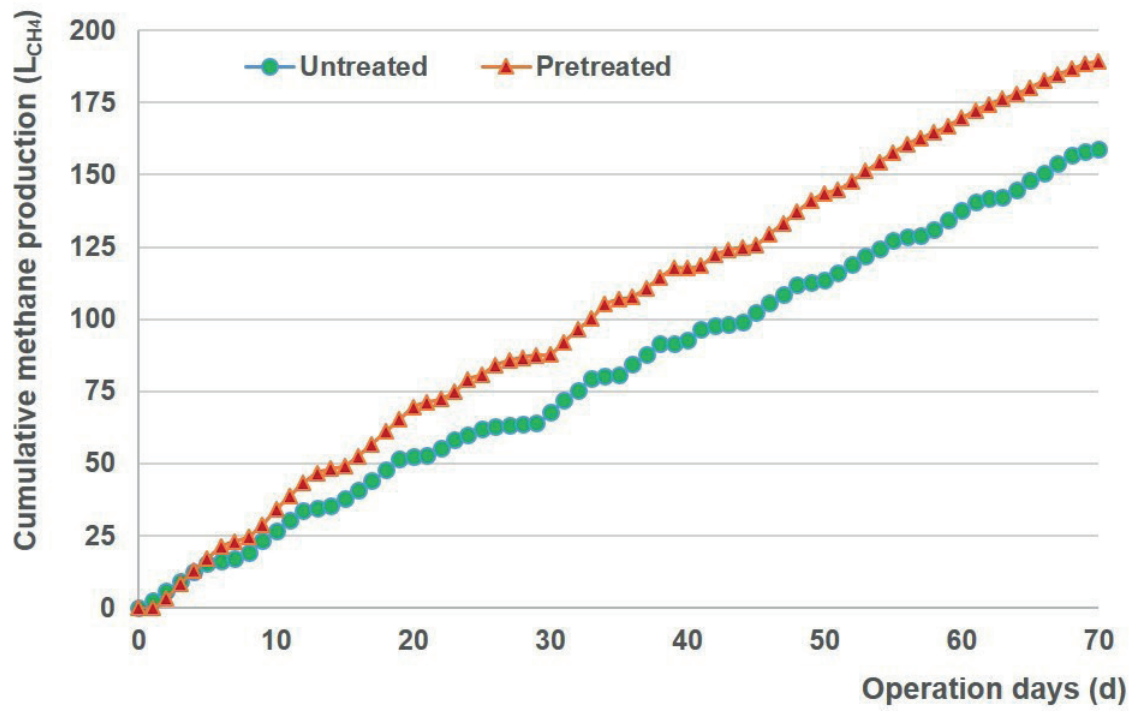

FIGURE 3: $\mathrm{CH}_{4}$ production of untreated and pretreated solid residues during the long-term AD process (HRT 20d).

uable fatty acids for successive platform chemicals production.

The solid residue fed into the anaerobic digesters assured process stability (no acidification phenomena occurred) despite the short HRT of $20 \mathrm{~d}$. The weakening of the lignocellulosic matrix by the thermal pre-treatment had a positive impact on the anaerobic conversion increasing significantly methane production rate in particular during weekend, when feeding was stopped. During the Project, assessment of the hygienic properties of digestate (in terms of Salmonella and E.coli concentration) will be performed to assure a "safe" digestate to be recycled in agriculture, drastically reducing environmental waste impact, one of the prior societal challenges in many part of the world.

\section{ACKNOWLEDGEMENTS}

The REVENUE Project was funded by Fondazione Cariplo contract No. 2019-2407.

\section{REFERENCES}

Agler, M.T., Wrenn, B.A., Zinder, S.H., \& Angenent L.T., 2011. Waste to bioproduct conversion with undefined mixed cultures: the carboxylate platform. Trends in Biotechnology 29, 70-78. doi: 10.1016/j. tibtech.2010.11.006

Alibardi, L., Astrup, T.F., Asunis, F., Clarke, W.P., de Gioannis, G., et al., 2020. Organic waste biorefineries: Looking towards implementation. Waste Management 114, 274-286.

APHA, (1998). Standard Methods for the Examination of Water and Wastewater, twentieth ed., Washington DC.

Ariunbaatar J., Panico, A.,Yeh, D.H., Pirozzi,F., Lens, P.N., \& Esposito, G. 2015. Enhanced mesophilic anaerobic digestion of food waste by thermal pretreatment: Substrate versus digestate heating. Waste Management 46,176-181.

Arslan, D., Steinbusch, K.J.J., Diels, L., Hamelers, H.V.M., Strik, D.P.B.T.B., Buisman, C.J.N., \& De Wever, H., 2016. Selective shortchain carboxylates production: A review of control mechanisms to direct mixed culture fermentations. Critical Reviews in Environmental Science and Technology 46(6), 592-634.

Braguglia, C.M., Gagliano, C., \& Rossetti, S., 2012. High frequency ultrasound pretreatment for sludge anaerobic digestion: Effect on floc structure and microbial population. Bioresource Technology $110,43-49$.
Braguglia, C.M., Gallipoli, A., Gianico, A., \& Pagliaccia, P., 2018. Anaerobic bioconversion of food waste into energy: A critical review. Bioresource Technology 248, 37-56. https://doi.org/10.1016/j.biortech.2017.06.145

Capson-Tojo, G., Rouez, M., Crest, M., Steyer, J.-P., Delgenes, J.-P., and Escudie, R., 2016. Food waste valorization via anaerobic processes: a review. Rev. Environ. Science and Bio/Technol. 15(3), 499-547

Carrere, H., Antonopoulou, G., Affes, R., Passos, F., Battimelli, A., Lyberatos, G., Ferrer, I. 2016. Review of feedstock pretreatment strategies for improved anaerobic digestion: from lab-scale research to fullscale application. Bioresour. Technol. 199, 386-397.

Cesaro, A., Belgiorno, V., 2020. Ozone pretreatment for the anaerobic digestion of organic solid waste. Detritus 12, 51-56. DOI 10.31025/2611-4135/2020.13990Coma, M., Martinez-Hernandez, E., Abeln, F., Raikova, S., Donnelly, J., Arnot, T. C., Allen, M.J., Hong, D.D., \& Chuck, C.J., 2017. Organic waste as a sustainable feedstock for platform chemicals. Faraday Discussions 202, 175-195. http://dx.doi.org/10.1039/C7FD00070G.

Crognale, S., Braguglia, CM., Gallipoli, A., Gianico, A., Rossetti, S. and Montecchio, D., 2021. Direct Conversion of Food Waste Extract into Caproate: Metagenomics Assessment of Chain Elongation Process. Microorganisms 9(2), 327; https://doi.org/10.3390/ microorganisms9020327Dubois, M., Gilles, K.A., Hamilton, J.K., Rebers, P.A., \& Smith, F., 1956. Colorimetric method for determination of sugars and related substances, Analytical Chemistry 28, 350-356.

Eurostat (2020). Renewable energy in the EU in 2018. News Release 17. https://ec.europa.eu/eurostat/documents/2995521/10335438/823012020-AP-EN.pdf/292cf2e5-8870-4525-7ad7-188864ba0c29.

Gagliano, M.C., Braguglia, C.M., Gallipoli, A., Gainico, A., Rossetti, S., 2015. Microbial diversity in innovative mesophilic/thermophilic temperature-phased anaerobic digestion of sludge. Environmental Science and Pollutution Research 22, 7339-7348.

Gallipoli, A., Braguglia, C.M., Gianico, A., Montecchio, D., Pagliaccia, P., 2020. Kitchen waste valorization through a mild-temperature pretreatment to enhance biogas production and fermentability: kinetics study in mesophilic and thermophilic regimen. J. Environ. Sci. $89,167-179$.

Gianico, A., Braguglia, C.M., Cesarini, R., \& Mininni, G., 2013. Reduced temperature hydrolysis at $134^{\circ} \mathrm{C}$ before thermophilic anaerobic digestion of waste activated sludge at increasing organic load. Bioresource Technology 143, 96-103.

Kannengiesser, J., Kuhn, C., Mrukwia, T., Stanojkovski, D., Jager, J., Schebek, L., 2018. Generation of bio-based products from omsw by using a solid-liquid separation technique and an anaerobic treatment, Detritus. 4, 78-89.

Kleerebezem, R., \& Van Loosdrecht, M.C.M., 2007. Mixed culture biotechnology for bioenergy production. Current Opinion in Biotechnology 18, 207-212. 
Kleerebezem, R., Joosse, B., Rozendal, R., \& Van Loosdrecht, M.C.M., 2015. Anaerobic digestion without biogas? Reviews in Environmental Science and Biotechnology 14, 787-801.

Lee, W.S., Chua, A.S.M., Yeoh, H.K. \& Ngoh, G.C., 2014. A review of the production and applications of waste-derived volatile fatty acids. Chemical Engineering Journal 235, 83-99.

Loow, Y. L., Wu, T. Y., Jahim, J. M., Mohammad, A. W., \& Teoh, W. H. 2016. "Typical conversion of lignocellulosic biomass into reducing sugars using dilute acid hydrolysis and alkaline pretreatment," Cellulose 23(3), 1491-1520. DOI: 10.1007/s10570-016-0936-8.

Marshall, C.W., LaBelle, E.V., \& May, H.D., 2013. Production of fuels and chemicals from waste by microbiomes. Current Opinion in Biotechnology 24(3), 391-397.

Montecchio, D., Gallipoli, A., Gianico, A., Mininni, G., Pagliaccia, P. \& Braguglia, C.M., 2017. Biomethane potential of food waste: modeling the effects of mild thermal pretreatment and digestion temperature. Environmental Technology 38(11), 1452-1464.

Morgan-Sagastume, F., Pratt, S., Karlsson, A., Cirne, D., Lant, P., \& Werker, A., 2011. Production of volatile fatty acids by fermentation of waste activated sludge pre-treated in full-scale thermal hydrolysis plants. Bioresource Technology 102(3), 3089-3097.

Pagliaccia P., Gallipoli, A., Gianico, A., Montecchio, D., \& Braguglia, C.M., 2016. Single stage anaerobic bioconversion of food waste in mono and co-digestion with olive husks: Impact of thermal pretreatment on hydrogen and methane production. International Journal of Hydrogen Energy 41(2), 905-915. http://dx.doi.org/10.1016/j. ijhydene.2015.10.061

Pagliaccia, P., Gallipoli, A., Gianico, A., Gironi, F., Montecchio, D., Pastore, C., di Bitonto, L., \& Braguglia, C.M., 2019. Variability of food waste chemical composition: Impact of thermal pretreatment on lignocellulosic matrix and anaerobic biodegradability. Journal of Environmental Management 236, 100-107.

Pecorini, I., Baldi, F., Carnevale, E.A., \& Corti, A., 2016. Biochemical methane potential tests of different autoclaved and microwaved lignocellulosic organic fractions of municipal solid waste. Waste Management 56, 143-150.

Pfaltzgraff, L.A., De Bruyn, M., Cooper, E.C., Budarin, V., \& Clark, J.H. 2013. Food waste biomass: A resource for high-value chemicals. Green Chemistry 15, 307-314.
Romero-Cedillo L., Poggi-Varaldo H.M., Ponce-Noyola T., Ríos-Leal E., Ramos-Valdivia A.C., Cerda-García Rojas C.M., \& Tapia-Ramírez J., 2017. A review of the potential of pretreated solids to improve gas biofuels production in the context of an OFMSW refinery. Journal of Chemical Technology and Biotechnology 92, 937-958.

Smith, P.K., Krohn, R.I., Hermanson, G.T., Mallia, A.K., Gartner, F.H. Provenzano, M.D., Fujimoto, E.K., Goeke, N.M., Olson, B.J., Klenk ,D.C., 1985. Measurement of protein using bicinchoninic acid. Analytical Biochemistry 150(1), 76-85.

Steinbush K. J. J., Hamelers, H. V. M., Plugge, C. M., \& Buisman, C. J. N., 2011. Biological formation of caproate and caprylate from acetate: fuel and chemical production from low grade biomass. Energy \& Environmental Science 4, 216-224. https://doi.org/10.1039/ COEE00282H.

Tonanzi, B., Gallipoli, A., Gianico, A., Montecchio D., Pagliaccia, P., Di Carlo, M., Rossetti, S., \& Braguglia, C.M., 2018. Long-term anaerobic digestion of food waste at semi-pilot scale: Relationship between microbial community structure and process performances. Biomass and Bioenergy 118, 55-64. https://doi.org/10.1016/j. biombioe.2018.08.001.

Tonanzi, B., Braguglia, C.M., Gallipoli, A., Montecchio, D., Pagliaccia, P., Rossetti, S., Gianico, A., 2020. Anaerobic digestion of mixed urban biowaste: The microbial community shift towards stability. New Biotechnology 55, 108-117. https://doi.org/10.1016/j. nbt.2019.10.008.

Valentino, F., Moretto, G., Gottardo, M., Pavan, P., Bolzonella, D., \& Majone, M., 2019. Novel routes for urban bio-waste management: A combined acidic fermentation and anaerobic digestion process for platform chemicals and biogas production. Journal of Cleaner Production 220, 368-375.

Zacharof, M.P. \& Lovitt, R.W., 2013. Complex Effluent Streams as a Potential Source of Volatile Fatty Acids. Waste and Biomass Valorization 4(3), 557-581.

Zhang, Y., Banks, C.J., Heaven, S., 2012. Co-digestion of source segregated domestic food waste to improve process stability. Bioresour. Technol. 114, 168-178.

Zhang D., Jiang H., Chang J., Sun J., Tu W., \& Wang H., 2019. Effect of thermal hydrolysis pretreatment on volatile fatty acids production in sludge acidification and subsequent polyhydroxyalkanoates production. Bioresource Technology 279, 92-100. 